\title{
Research on Energy Cooperation Strategy between China and Central Asia Based on Xinjiang
}

\author{
Gulinaer•Yusufu \\ Xinjiang University Center for Innovation Management Research of Xinjiang, School of Economics \& \\ Management, Urumqi, Xinjiang, 830046 \\ Email: gulnur_y@sina.com
}

Keywords: energy cooperation; control charts; process capability

\begin{abstract}
As the key cooperation node for the construction of the Silk Road Economic Belt, the five Central Asian countries have a good energy base and conditions for cooperation. From different perspectives, this paper analyzes the major powers and Central Asian national conditions for the China-Central Asia energy cooperation strategy, influences the establishment of a strategic framework for energy cooperation between China and Central Asia in the context of the Silk Road Economic Belt, discusses the implementation process, model selection, and promotion strategies of China-Central Asia energy cooperation, and clarifies the China Silk Road. The mission and role of the regional economic and energy companies in the economic belt have brought forward key elements for the promotion of energy cooperation strategy.
\end{abstract}

\section{Introduction}

At present, global economic integration and regional economic and trade cooperation are constantly escalating. The turmoil in the energy market has intensified. The world is competing for energy one after another. The international geopolitics has become more complex in an era. Under the strategic framework of jointly building the Silk Road Economic Belt, energy cooperation is The strategic breakthrough in the cooperation and development between China and Central Asia will realize national interests and promote regional common prosperity and development. Systematic studies and in-depth discussions on the issues of cooperation, scope, goals, positioning, and ways of achieving the China-Asia energy cooperation strategy; Studying the strategic choice of energy cooperation between China and Central Asia at different stages of the construction of the Silk Road Economic Belt And innovation, defining the respective role orientation, behavioral characteristics, and roles and tasks in the process of Central Asian energy cooperation with government-led and active participation of enterprises from a theoretical perspective, clarifying the development direction and evolution path of the energy cooperation strategy in Central Asia, and promoting China's and China's energy cooperation strategy. The sustainable implementation of the sustainable development of sub-energy cooperation and the strategy of the Silk Road Economic Belt has important theoretical and practical significance.

\section{China - Strategic Foundation and Influencing Factors of Energy Cooperation in Central Asia}

The energy resources of the five countries in Central Asia are very rich. Among them, oil and gas resources are mainly distributed in Kazakhstan, Turkmenistan, and Uzbekistan. Kyrgyzstan and Tajikistan have less oil and gas resources, but the two countries have abundant water, coal resources and energy transit channels. Location Advantage. Statistics from BP's world energy show that: At the end of 2012, the proven reserves of five Central Asian countries were 3.12 billion barrels, accounting for $1.87 \%$ of the world's proven oil reserves; and the proven reserves of natural gas was 187.3 trillion cubic meters, which is the world's natural gas. $10.62 \%$ of reserves. According to experts' predictions, the actual oil and gas reserves in the five Central Asian countries are far greater than the proven reserves. In the future, the proportion of oil and natural gas reserves in the five 
Central Asian countries in the world will continue to increase. Central Asia has great market potential in oil and gas exploration and development, oil and gas deep processing, petrochemicals, oil and gas pipeline construction and transformation, oil and gas engineering services and technological innovation, and petroleum equipment manufacturing, providing a vast market space for oil and gas cooperation between China and other countries in the world. China is a country with a shortage of oil and gas resources. Oil and gas demand has been growing steadily. Currently, the external dependence on oil and natural gas is 58\% and 32\% respectively. Central Asia borders on China and is the core area of the Silk Road Economic Belt. The strategy for the construction of the Silk Road Economic Belt provides a powerful impetus for China's oil and gas cooperation in Central Asia [1].

The Silk Road Economic Belt is a national strategy proposed by China. The realization of this grand strategy requires the close cooperation of countries along the Silk Road. Therefore, the implementation of the China-Central Asia energy cooperation strategy under the background of the construction of the Silk Road Economic Belt will be affected by multiple factors. The main factors are:

(1) Great power factor. Central Asia is located between Russia, China, Iran, and other countries. The geographical location is very special. Central Asia, especially the Caspian Sea region, is rich in oil and natural gas resources. The cooperation with oil and natural gas resources in this region is a goal for all countries in the world to seek economic growth. Benefits, a good way to ensure the country's energy security. Therefore, China's energy cooperation in Central Asia is bound to be affected and restricted by other countries. As far as the Central Asian countries are concerned, the exploration and development of oil and gas resources has long relied on international oil companies as a whole, and this has become a region where the world's major nations compete for energy resources and geopolitical competition. Russia, the United States, the European Union, Japan and other countries are in the energy consumption structure, energy security, and Differences in external energy strategies and other aspects are also fully reflected in the energy competition and cooperation in this region. The goal of building a mutually beneficial win-win situation for the Silk Road Economic Belt runs counter to the thinking of the zero-sum game in certain countries and exacerbates China's Difficulties in the cooperation of oil and gas resources in Central Asia.

(2) Central Asian factors. Based on the five Central Asian countries themselves, subjectively, they all emphasized and affirmed that the co-construction of the Silk Road Energy Economic Belt can promote the prosperity and stability of the country, but it is subject to different levels of political and economic development, energy resources, potential, and humanities. Affected by social factors, the actual participation of countries depends on how much interest the country can bring to the co-construction of the Silk Road Economic Belt. Objectively, due to history and legacy, there are still some contradictions and disputes among the Central Asian countries in the demarcation of borders, resource allocation, policy coordination, etc., and set up inter-regional transnational energy cooperation in the process of the construction of the Silk Road Economic Belt. Different degrees of obstacles. From the perspective of Central Asia, the five Central Asian countries are rich in oil and gas resources. Central Asian countries, which mainly rely on trading of oil and gas resources, are gradually transforming their cooperation and cooperation with foreign countries and foreign companies, and shifting from extensive energy cooperation to intensive Type, sustainable development and cooperation, changes in the cooperation model brought about by this transformation, and the corresponding role-switching between government and enterprises, and the existing political and economic environment in Central Asia is still difficult to adapt [2].

\section{The Strategic Path to Solve the Energy Cooperation Obstacle in the Xinjiang-Central Asian Silk Road Economic Belt}

The drastic changes in the international situation have prompted China to continue to break through the existing limitations of the Central Asian strategy and increase bilateral energy cooperation to a mutually beneficial and win-win goal. The strategy of co-constructing the Silk Road Economic Belt put forward the idea of "promoting regional cooperation with each other from 
point to point, from line to film, and gradually forming a regional cooperation," and pointed out the direction and basic path for energy cooperation between Xinjiang and Central Asia. The International Energy Agency (IEA) proposed that energy diversity, market efficiency, and flexibility are the basic conditions for long-term energy security. Free and open energy policies are the institutional guarantees for energy security in the world. The strategic concept of the Silk Road Economic Belt focuses on energy cooperation. The plan includes political coordination, policy communication, elimination of trade barriers, infrastructure interconnection, strengthening of the financial system, and exchanges in the humanities field. It has strong tolerance. Sexuality and openness. In this context, the energy dialogue between Xinjiang and Central Asian countries and regions will be strengthened, an open and harmonious energy cooperation environment will be formed, and the two sides will strengthen their ideas on energy security and form a consensus that can effectively prevent and reduce the perceived differences in energy security and its Derivative energy policy risks promote the pragmatic progress in the energy cooperation between Xinjiang and Central Asia. On this basis, we should also actively expand energy diplomacy. Based on the national level, we make full use of the strategy of the Silk Road Economic Belt and the appeal of the Shanghai Economic Cooperation Organization (SCO) and the Central Asia Regional Economic Cooperation Mechanism (CAREC) to deepen the multilateral strategic partnership and strengthen the good-neighborly relations with the Central Asian countries. The friendly and cooperative relations will be signed and improved with high-level bilateral agreements on investment protection, judicial assistance, double taxation evasion, etc., to avoid maximum losses due to fluctuations and changes in their internal energy policies. Based on the level of Xinjiang, the political, economic, and cultural exchanges between Xinjiang and Central Asian countries and regions should be vigorously promoted, relying on the advantages of the Silk Road Economic Belt and the use of ties to enhance the complementary exchanges between Xinjiang and the Central Asian countries and enhance mutual Relying on its attributes, establish a long-term and good strategic partnership, while smoothly promoting cooperation in oil and gas resources, and avoid positive participation in the energy competition of major countries in Central Asia [3].

The Silk Road Economic Belt Strategy plays an important role in advancing the implementation of the national energy strategy in Xinjiang and transforming Xinjiang's position in China's energy cooperation with Central Asia. Under the strategic direction of jointly building the Silk Road Economic Belt, Xinjiang will promote the construction of the "12th Five-Year" energy strategic base. It will strive to shift from oil and gas transmission bridges to oil and gas transfer stations, and will turn the spearhead of industrial development toward oil and gas resources according to the characteristics of the industrial structure in the region. The middle and lower reaches of the industry will realize the interaction and response in the development direction between Xinjiang, China's interior and Central Asian countries, and achieve the goal of mutual benefit and common development. To this end, Xinjiang will internally improve the industrial structure of Xinjiang, increase the construction of the energy resources industry in the middle and lower reaches, enrich the types of products in the middle and lower reaches, and strengthen the overall correlation between the energy resources industry, Xinjiang industry, and the tertiary industries; Building the advantages of the Silk Road, while advancing the construction of energy strategic bases, expanding the areas of energy cooperation with Central Asia, expanding from the current low value-added oil and gas resources trade to the development of fine chemicals, manufacturing, textile and agricultural products processing, etc. A wide range of downstream industry cooperation and the development of two-way trade can truly transform the bridge from oil and gas transmission in Xinjiang into the main body of energy cooperation in Central Asia, and become a resource transformation base for energy cooperation with the Central Asian countries on the Silk Road Economic Belt. At the same time, Xinjiang shall actively build an international regional financial center based on the resources and energy channels of the Silk Road Economic Belt and the national energy base, provide convenient financial services for energy trade and energy cooperation and investment, and intensify efforts to promote "oil. Chemical Industry Park, "World Oil City", "China Textile City”, "Special Fruits Export Processing Base”, "Fashion Garment City”, "Small-scale 
Home Appliances Export Processing Base” and other characteristic oil city construction; make full use of "two markets" "Two kinds of resources" to promote the diversified development of Xinjiang's energy strategic bases and provide the basis for Western Union's eastward development, so as to achieve the development goals of the Silk Road Economic Belt's strategic multi-sectoral complementarity, mutual benefit, and win-win cooperation.

At the "2014 China - Xinjiang Silk Road Economic Belt Financial Center Construction High-Level Seminar" held on November 8, 2014, it has been clearly stated that it will plan to establish a Central Asian energy resource trading platform[4] to promote and protect Xinjiang and China. The long-term stability and sustainable development of the Asian energy cooperation are of great significance. The platform construction can rely on the advantages of location, location, energy resources, and humanities in Xinjiang and Central Asia under the strategy of the Silk Road Economic Belt, and cooperation in the production, circulation, transaction, logistics, and capital settlement of Xinjiang and Central Asia with energy as the link. The process is organically linked to form an energy resource trading and information integrated service network platform. At the same time, in order to ensure the smooth operation and continuous improvement of the energy cooperation information platform, a Central Asia Energy Information Research Institute with government-led, enterprises, and research institutes should be established to meet the political, economic, social, and cultural needs of the Central Asian region. , geography development, energy resources, and other research [5] provide rich reference and reference materials for the construction and improvement of energy cooperation information platform to enhance initiative and reduce blindness, and provide energy cooperation for Xinjiang and Central Asia Information support and decision-making basis.

\section{Conclusion}

The Silk Road Economic Belt is an upgraded version of regional economic and trade cooperation. It focuses on cooperation and development in energy and other fields, and provides a broad connotation and extension for energy cooperation in Xinjiang and Central Asia, and also provides a broad space for energy cooperation between the two sides. Although the prospects are promising, the energy cooperation between the two sides will still be subject to the complex energy cooperation environment in Central Asia, Xinjiang's unique economic model and industrial structure, and other internal factors. It is necessary to realize the Silk Road economic belt of mutual benefit and win-win cooperation between Xinjiang and Central Asia. To build goals together, it is necessary to strengthen energy dialogues, expand energy diplomacy, advance the process of building energy strategic bases in Xinjiang, and accelerate the establishment and improvement of an information platform for energy cooperation in Central Asia.

\section{References}

[1] Zuo Fengrong. Opportunities and Challenges in Building the "Silk Road Economic Belt" [J]. Contemporary World, 2014, (5): 12-15.

[2] Wang Baozhong, He Liancheng, Li Zhongmin. "Integration of the New Silk Road Economic Belt" strategic path and implementation of countermeasures [J]. Economic and vertical, 2013, (11): 60-65.

[3] Li Qin. Motivation and prospects of the multi-variable energy trade cooperation between Xinjiang and Central Asia-Russia within the framework of SCO[J]. Rural Economy \& Technology, 2009, (8):48-49

[4] Guo Xiaobing, Gao Zhigang. Analysis of the Construction of the Core Area of Xinjiang Silk Road Economic Belt [J]. Journal of Xinjiang University of Finance and Economics, 2014, (2): 21-27.

[5] Pang Changwei. Energy Cooperation: A Breakthrough in the "Silk Road Economic Belt" Strategy [J]. Journal of Xinjiang Normal University (Philosophy and Social Science Edition), 2014, (2): 11-18. 